\title{
Optimal subsidy policy for accelerating the diffusion of green products
}

\author{
Hongguang Peng \\ School of Economics \& Management, Zhejiang University of Science and Technology (China) \\ iamphg@126.com
}

Received: March 2013

Accepted: March 2013

\section{A bstract:}

Purpose We consider a dynamic duopoly market in which two firms respectively produce green products and conventional products. The two types of product can substitute each other in some degree. Their demand rates depend on not only prices but the consumers' increasing environmental awareness. Too high initial cost relative to conventional products becomes one of the major obstacles that hinder the adoption of green products. The government employs subsidy policy to trigger the adoption of green products. The purpose of the paper is to explore the optimal subsidy strategy to fulfill the government's objective.

Design/mathoddogy/approadr We suppose the players in the game employ open-loop strategies, which make sense since the government generally cannot alter his policy for political and economic purposes. We take a differential game approach and use backward induction to analyze the firms' pricing strategy under Cournot competition, and then focus upon a Stackelberg equilibrium to find the optimal subsidy strategy of the government.

Findings: The results show that the more remarkable the energy or environmental performance, or the bigger the initial cost of green products, the higher the subsidy level should be. Due to the increasing environmental awareness and the learning curve, the optimal subsidy level decreases over time. 
Researd limitations/implications: In our model several simplifying assumptions are made to keep the analysis more tractable. In particular, we have assumed only one type of green product. In reality several types of product with different energy or environmental performances exist. Our research can be extended in future work to take into account product differentiation on energy or environmental performance and devise a discriminatory subsidy policy accordingly.

Originality/value In the paper we set the objective of the government as minimizing the total social cost induced by the energy consumption or environmental side effect and government expenditure. In addition, we assume the price of conventional products is variable and examine the Cournot competition between the two firms. This study can provide more valuable managerial insights into improving the design of subsidy policy.

Keywards: price subsidy, Cournot competition, open-loop Stackelberg game, differential game

\section{Introduction}

The issues on energy conversation and environment protection are drawing more and more attention from public institutions, firms and consumers. More social endeavor are devoted into fields of green design, production and supply chain management (See Baines, Brown, Benedetettini \& Ball, 2012; Luthra, Kumar, Kumar \& Haleem, 2011 for more). Many firms have innovated and developed greener products to replace conventional products. But these innovative products are generally priced high relative to conventional products due to enormous upfront R\&D and production cost. Thus too high price becomes one of the major obstacles that hinder the adoption of green products. For example, researches on many plug-in hybrid electric vehicle (PHEV) cost estimates suggest a cost premium of around $30-80 \%$ above conventional vehicles. A survey indicates that if PHEVs are available at a $15 \%$ cost premium over conventional vehicles, they would significantly penetrate the vehicle market even without a climate policy (Karplus, Paltsev \& Reilly, 2010).

In order to reduce the energy consumption and environment pollution and accelerate the market diffusion of environmentally friendly products, lots of countries are employing price subsidy or taxes rebate instruments. For instance, the American Recovery and Reinvestment Act of 2009 provides a tax credit of $\$ 2500$ per plug-in hybrid electric vehicle sold (requires at least $4 \mathrm{kWh}$ battery capacity) and an additional $\$ 417$ for each additional kWh of battery capacity in excess of $4 \mathrm{kWh}$ (capped at $\$ 7500$ for vehicles with a gross vehicle weight less than 14,000lb) (Peterson \& Michalek, 2013). In China from June, 2012 to May, 2013, household inverter air conditioner per unit can get subsidy varying from 180 Yuan to 400 Yuan according 
to different cooling capacities and energy efficiencies (Ministry of Finance of the People's Republic of China, 2012).

The government's subsidy policy aims to reducing the actual price the consumers afford for the green product, increasing its competitiveness, and accelerating its diffusion. The practical effects of subsidy policy in some regimes are identified by some research. Zhang, Song and Hamori (2011) construct panel data from an 11-year data set on all 47 prefectures of Japan, covering the period 1996-2006, and use this data set to analyze the factors affecting photovoltaic (PV) system diffusion. Their empirical results show that government subsidy policies are seemingly of critical importance in promoting photovoltaic system diffusion in Japan. In Taiwan, two national incentive programs (1986-1991, 2000-present) are initiated by the government to promote utilization of solar water heaters (SWHs). In general, the two subsidy programs are considered be the driving force on local market expansion and have a drastic effect on popularization of SWHs in Taiwan (Chang, Lin, Lee \& Chung, 2011).

A very successful model on diffusion of innovation was early proposed by Bass (1969). The Bass model expresses change in cumulative sales over time in a new marketplace in which the innovation is sold to first-time purchasers. In the model the cumulative sales depend on the number of previous adopters and the total market potential. Later a number of researchers have extended the Bass model in incorporating market competition combining variables such as price, advertising and product characteristics (see Kim, Bridges \& Srivastava, 1999; Peres, Muller \& Mahajan, 2010 for more). Game theory has been introduced into this research field. For instance, Dockner and Jørgensen (1988) deal with the determination of optimal dynamic pricing policies in an oligopolistic market using differential game theory, and analyze three basic classes of sales dynamics: competition with price effects only, competition with price as well as adoption effects, and competition with adoption effects only. Levin, McGill and Nediak (2009) provide insights about equilibrium price dynamics under different levels of competition, asymmetry between firms, and multiple market segments with varying properties.

Some authors theoretically analyze the impacts of subsidy instrument. Kalish and Lilien (1983) propose a model to investigate analytically the effects of a price subsidy over time on the rate of market diffusion. The model considers word-of-mouth effects and learning curve. The results show that if there is positive diffusion effect, price increases in time, while if market saturation causes demand to decline over time price decreases in time. Cesare and Liddo (2001) state the subsidy problem as a leader-follower game by introducing an additional decision variable to the firm: the advertising effort.

How does the government subsidy influence the price of the green products? Subsidies raise buyers' willingness-to-pay, and by itself this might cause firms to charge higher prices (Orzen \& Sefton, 2003). The higher price might counteract the effect of the subsidy policy. Jørgensen and Zaccour (1999) deal with a problem of a government that wishes to maximize the 
cumulative sale of the green technology sold to private households by the terminal date of the government program. Jørgensen and Zaccour (1999) extend previous studies by introducing guaranteed buys and a substitute product (an existing technology), and find out (in the case of a constant price of the alternative technology) that an optimal subsidy rate is decreasing over time. Based on an environmentally differentiated products model, Toshimitsu (2010) has shown a paradoxical case generated by a consumer-based environmental subsidy where the subsidy policy degrades the environment and is (not) socially optimal if the marginal social valuation of environmental damage is sufficiently small (large, respectively). Cantono and Silverberg (2009) set up a network model of new technology diffusion that combines contagion among consumers with heterogeneity of agent characteristics. They argue that the introduction of a subsidy policy seems to be highly effective for a given high initial price level only for learning economies in a certain range. Lorentziadis and Vournas (2011) develop a model to determine the required subsidy in order to achieve a specific replacement target of old polluting vehicles within a certain time framework, and derive the required subsidy level, replacement rate and program duration.

Jørgensen and Zaccour (1999), Cantono and Silverberg (2009) and Lorentziadis and Vournas (2011) consider the case that the alternative technology has a constant price and leave out the impact of the subsidy on the price adjustment of the alternative technology. In practice the occurrence of government subsidy change the market competition status and the new situation undoubtedly influences the price of the old technology. Therefore we should take into account the interactions between the two technologies and pricing dynamics. We assume that the green products and alternative technology can substitute in some degree and the price of conventional products changes quite dynamically over the competition situation.

In most previous studies the objectives of the government are to achieve the amount target that the green products sell in fixed period by given budget. This might lead to such a paradox as the subsidy policy degrades the environment shown in Toshimitsu (2010). The reason partly lies in that the government subsidy reduces the price of green products so that they can sell more. The increasing sales volume offsets the reduction of energy consumption per unit energy saving product. In our paper we set the objective of the government as minimizing the total social cost induced by the energy consumption of the products and government expenditure. The purpose of the paper is to explore the optimal subsidy strategy to fulfill the government's objective.

The rest of the paper is organized as follows. In section 2 the set-up is laid out. Section 3 formulates the Stackelberg differential game to find the equilibrium. Section 4 presents an illustrative example to show how the optimal price and subsidy vary with time. Section 5 concludes. 


\section{The set-up}

We consider a duopoly market in which one firm produces green products and another firm produces conventional products. The two types of product satisfy consumers' same needs, that is to say, they can substitute each other in some degree. Let subscript $i$ and $j$ denote green products and conventional products separately in this work. Similar to the linear demand function used by Cellini and Lambertini (2002), we suppose the demand rates at time $t$ of green products and conventional products are respectively

$$
\begin{gathered}
\dot{x}_{i}(t)=\alpha_{i}-\beta_{i}(t) p_{i}(t)+\gamma_{i} p_{j}(t) \\
\dot{x}_{j}(t)=\alpha_{j}-\beta_{j}(t) p_{j}(t)+\gamma_{j} p_{i}(t)
\end{gathered}
$$

Where $x(t)$ denotes the market cumulative sales of the products from continuous time $0 t$ to and $p(t)$ denotes the price at the time $t$. Coefficients $\alpha$ and $\gamma$ are positive constants. Coefficient $\gamma$ represents the degree of substitutability between green products and conventional products. Coefficient $\beta(t)$ varies with the time and incorporates the consumers' environmental awareness. As environmental awareness increases continually, the consumers are more willing to buy green products even if they have to pay more (Conrad, 2005). Thus the price elasticity

of the products is invariable no longer and furthermore we have $\frac{\partial \beta_{i}(t)}{\partial t}<0, \frac{\partial \beta_{j}(t)}{\partial t}>0$. We assume $\beta_{i}(t) \beta_{j}(t)-\gamma_{i} \gamma_{j}>0$ to make sure that the prices and sales of two types of product maintain positive.

Considering learning curve and scale effect we suppose that unit cost of the two types of product decreases with the increasing production volume, $c_{i}(t)=c_{i}{ }^{0}-c_{i} x_{i}(t)$, $c_{j}(t)=c_{j}^{0}-c_{j} x_{j}(t)$, where $c_{i}^{0}, c_{j}^{0}, c_{i}$ and $c_{j}$ are positive constants, and $c_{i}^{0}>c_{j}^{0}$, which means the unit cost of green products is higher than conventional products at the time 0 .

At the beginning of entering into market, the green products are at a disadvantage when competing with conventional products due to higher cost. Since the green products consume less resources and energy, and have less side effects on environment, the government subsidize the consumers buying the green products $s(t)$ per unit of green product to stimulate its market diffusion. The subsidy program proceeds from time $O$ to $T$. When making subsidy policy, the government cannot disregard the response of the firm producing conventional products. The subsidy as the equivalent of the price reduction of green products no doubt leads to the price adjustment of the conventional products. Demand and cost of the two types of product vary as the time goes on. Given the subsidy $s(t)$ each firm will certainly adjust their price considering the opponent's response in order to maximize his own profit. 
Let $S(t)$ denotes the cumulative subsidy expenditure of the government during the period from

time 0 to $t$. Then we have $S(T)=\int_{0}^{T} s(t) \dot{x}_{i}(t) d t, S(0)=0$. The objective of the government is to minimize the total social cost, $\min J_{g}=q_{i} x_{i}(T)+q_{j} x_{j}(T)+S(T)$, where $q_{i}$ and $q_{j}$ respectively refer to the social cost incurred by energy consumption and environment impact of unit green product and conventional product. The social cost can be calculated according to the report by World Bank (Sadeghi \& Ameli, 2012). Coefficient $q$ reflects energy or environmental performance of the products. A less $q$ means a better energy or environmental performance of the products. It is clear that $q_{i}<q_{j}$.

We suppose the players in the game employ open-loop strategies. Since the government generally cannot alter his policy for political and economic purposes we can assume he creditably precommits to its subsidy policy. Thus the firms make their decisions at the initial instant of the time and can stick to it unchangeably. So the open-loop supposition makes sense in this scenario.

\section{The Stackelberg differential game model}

In our Stackelberg game model the government takes the leader' role and the firms play the followers' role. When making subsidy policy, the government must estimate beforehand the price adjustment of the firms responding to the subsidy and the consumers' demand change. Given the government's subsidy policy, the two firms compete over prices. We can first use the backward induction to find the firms' pricing strategy under Cournot competition and then derive the government's optimal subsidy level.

\subsection{The optimal pricing strategy of green products}

The government subsidize the consumers that buy the green products $s(t)$ per unit of green product from time 0 to time $T$. After the implementation of subsidy policy the demand rate at the time $t$ can be written as

$$
\begin{aligned}
& \dot{x}_{i}(t)=\alpha_{i}-\beta_{i}(t)\left[p_{i}(t)-s(t)\right]+\gamma_{i} p_{j}(t) \\
& \dot{x}_{j}(t)=\alpha_{j}-\beta_{j}(t) p_{j}(t)+\gamma_{j}\left[p_{i}(t)-s(t)\right]
\end{aligned}
$$

Considering the subsidy duration is generally not long, we disregard the discount rate (Jørgensen \& Zaccour, 1999). The objective of the firm producing green products is to maximize his profit from time $O$ to $T$,

$$
\begin{gathered}
\max J_{i}=\int_{0}^{T}\left[\alpha_{i}-\beta_{i}(t)\left(p_{i}(t)-s(t)\right)+\gamma_{i} p_{j}(t)\right]\left(p_{i}(t)-c_{i}^{0}+c_{i} x_{i}(t)\right) d t \\
\text { s.t. } \quad p_{i}(t)>0
\end{gathered}
$$


We formulate Hamiltonian function of the firm producing green products

$$
\begin{aligned}
H_{i}= & {\left[\alpha_{i}-\beta_{i}(t)\left(p_{i}(t)-s(t)\right)+\gamma_{i} p_{j}(t)\right]\left(p_{i}(t)-c_{i}^{0}+c_{i} x_{i}\right)+} \\
& \lambda_{i}^{i}\left[\alpha_{i}-\beta_{i}(t)\left(p_{i}(t)-s(t)\right)+\gamma_{i} p_{j}(t)\right]+\lambda_{i}^{j}\left[\alpha_{j}-\beta_{j}(t) p_{j}(t)+\gamma_{j}\left(p_{i}(t)-s(t)\right)\right]
\end{aligned}
$$

where $\lambda_{i}^{i}$ and $\lambda_{j}^{j}$ are costate variables respectively associated with state variable $x_{i}(t)$ and $x_{j}(t)$. The costate equations are

$$
\begin{gathered}
\dot{\lambda_{i}^{i}}=-\frac{\partial H_{i}}{\partial x_{i}}=-c_{i}\left[\alpha_{i}-\beta_{i}(t) p_{i}(t)+\beta_{i}(t) s(t)+\gamma_{i} p_{j}(t)\right]=-c_{i} \dot{x}_{i}(t) \\
\dot{\lambda_{i}^{j}}=-\frac{\partial H_{i}}{\partial x_{j}}=0
\end{gathered}
$$

Using Equations (7) and (8) yields $\lambda_{i}^{i}(t)=-c_{i} x_{i}(t)+d_{i}, \lambda_{i}^{j}(t)=e_{i}$, where $d_{i}$ and $e_{i}$ are constants to be determined later. From transversality conditions $\lambda_{i}^{i}(T)=0, \lambda_{i}^{j}(T)=0$, we can obtain $d_{i}=c_{i} x_{i}(T), e_{i}=0$.

The Hamiltonian maximization condition is

$$
\begin{aligned}
\frac{\partial H_{i}}{\partial p_{i}}= & -\beta_{i}(t)\left(p_{i}(t)-c_{i}^{0}+c_{i} x_{i}+\lambda_{i}^{i}\right)+ \\
& \left(\alpha_{i}-\beta_{i}(t) p_{i}(t)+\beta_{i}(t) s(t)+\gamma_{i} p_{j}(t)\right)+\lambda_{i}^{j} \gamma_{j}=0
\end{aligned}
$$

From Equation (9) we can derive

$$
2 \beta_{i}(t) p_{i}(t)-\beta_{i}(t) s(t)-\gamma_{i} p_{j}(t)=\beta_{i}(t)\left(c_{i}^{0}-d_{i}\right)+\alpha_{i}
$$

\subsection{The optimal pricing strategy of conventional products}

The firm producing conventional products aims to

$$
\begin{gathered}
\max J_{j}=\int_{0}^{T}\left[\alpha_{j}-\beta_{j}(t) p_{j}(t)+\gamma_{j}\left(p_{i}(t) \rightarrow(t)\right)\right]\left[p_{j}(t)-c_{j}^{0}+c_{j} x_{j}(t)\right] d t \\
\text { s.t. } \quad p_{j}(t)>0
\end{gathered}
$$

The Hamiltonian function of the firm is given by

$$
\begin{aligned}
H_{j}= & {\left[\alpha_{j}-\beta_{j}(t) p_{j}(t)+\gamma_{j}\left(p_{i}(t)-s(t)\right)\right]\left(p_{j}(t)-c_{j}^{0}+c_{j} x_{j}\right)+} \\
& \lambda_{j}^{i}\left[\alpha_{i}-\beta_{i}(t)\left(p_{i}(t)-s(t)\right)+\gamma_{i} p_{j}(t)\right]+\lambda_{j}^{j}\left[\alpha_{j}-\beta_{j}(t) p_{j}(t)+\gamma_{j}\left(p_{i}(t)-s(t)\right)\right]
\end{aligned}
$$

where $\lambda_{j}^{i}$ and $\lambda_{j}^{j}$ are costate variables. 
The costate equations are

$$
\begin{aligned}
& \dot{\lambda}_{j}^{i}=-\frac{\partial H_{j}}{\partial x_{i}}=0 \\
& \dot{\lambda_{j}^{j}}=-\frac{\partial H_{i}}{\partial x_{j}}=-c_{j}\left[\alpha_{j}-\beta_{j}(t) p_{j}(t)+\gamma_{j}\left(p_{i}(t)-s(t)\right)\right]=-c_{j} \dot{x}_{j}(t)
\end{aligned}
$$

Using Equations (13) and (14) yields $\lambda_{j}^{i}(t)=e_{j}, \lambda_{j}^{i}(t)=-c_{j} x_{j}(t)+d_{j}$, where $e_{j}$ and $d_{j}$ are constants to be determined later. From transversality conditions $\lambda_{j}^{i}(T)=0, \lambda_{j}^{j}(T)=0$, we can obtain $d_{j}=c_{j} x_{j}(T), e_{j}=0$.

The Hamiltonian maximization condition is

$$
\begin{aligned}
\frac{\partial H_{j}}{\partial p_{j}}= & -\beta_{j}(t)\left(p_{j}(t)-c_{j}^{0}+c_{j} x_{j}+\lambda_{j}^{j}\right)+ \\
& {\left[\alpha_{j}-\beta_{j}(t) p_{j}(t)+\gamma_{j}\left(p_{i}(t)-s(t)\right)\right]+\lambda_{j}^{i} \gamma_{i}=0 }
\end{aligned}
$$

Equation (13) shows that

$$
2 \beta_{j}(t) p_{j}(t)+\gamma_{j} s(t)-\gamma_{j} p_{i}(t)=\beta_{j}(t)\left(c_{j}^{0}-d_{j}\right)+\alpha_{j}
$$

Let superscript $*$ denote the value of a variable in equilibrium. We have

Proposition 1. The optimal prices of green products and conventional products are given by the following equations respectively,

$$
\begin{aligned}
& p_{i}^{*}(t)=\frac{1}{4 \beta_{i}(t) \beta_{j}(t)-\gamma_{i} \gamma_{j}}\left\{\left(2 \beta_{i}(t) \beta_{j}(t)-\gamma_{i} \gamma_{j}\right) s(t)+\gamma_{i}\left[\beta_{j}(t)\left(c_{j}^{0}-d_{j}\right)+\alpha_{j}\right]+\right. \\
& \left.2 \beta_{j}(t)\left[\beta_{i}(t)\left(c_{i}^{0}-d_{i}\right)+\alpha_{i}\right]\right\} \\
& p_{j}^{*}(t)=\frac{1}{4 \beta_{i}(t) \beta_{j}(t)-\gamma_{i} \gamma_{j}}\left\{-\beta_{i}(t) \gamma_{j} s(t)+2 \beta_{i}(t)\left[\beta_{j}(t)\left(c_{j}^{0}-d_{j}\right)+\alpha_{j}\right]+\right. \\
& \left.\gamma_{j}\left[\beta_{i}(t)\left(c_{i}^{0}-d_{i}\right)+\alpha_{i}\right]\right\}
\end{aligned}
$$

Proof. By simultaneously solving Equations (10) and (16), we can easily get Eqs. (17) and (18). 
Since we have $\beta_{i} \beta_{j}-\gamma_{i} \gamma_{j}>0$, Equations (17) and (18) imply that $0<\frac{\partial p_{i}^{*}}{\partial s}=\frac{2 \beta_{i} \beta_{j}-\gamma_{i} \gamma_{j}}{4 \beta_{i} \beta_{j}-\gamma_{i} \gamma_{j}}<1$, $\frac{\partial p_{j}^{*}}{\partial s}=\frac{-\beta_{i} \gamma_{j}}{4 \beta_{i} \beta_{j}-\gamma_{i} \gamma_{j}}<0$. From the comparative analysis we can find out

- The government's subsidy induces the increase of green products' price, and the increase degree is less than the subsidy level. The actual price the consumers afford declines.

- The firm producing conventional products will reduce its price so as to compete against the component and maintain his competitive advantage.

Substituting Equations (17) and (18) into Equations (3) and (4), we can get the demand rate of the two types of product at time $t$,

$$
\begin{aligned}
\dot{x}_{i}(t)= & \alpha_{i}+\frac{2 \beta_{i}(t) \beta_{j}(t)-\gamma_{i} \gamma_{j}}{4 \beta_{i}(t) \beta_{j}(t)-\gamma_{i} \gamma_{j}} \beta_{i}(t) s(t)-\frac{2 \beta_{i}(t) \beta_{j}(t)-\gamma_{i} \gamma_{j}}{4 \beta_{i}(t) \beta_{j}(t)-\gamma_{i} \gamma_{j}}\left[\beta_{i}(t)\left(c_{i}^{0}-d_{i}\right)+\alpha_{i}\right]+ \\
& \frac{\beta_{i}(t) \gamma_{i}}{4 \beta_{i}(t) \beta_{j}(t)-\gamma_{i} \gamma_{j}}\left[\beta_{j}(t)\left(c_{j}^{0}-d_{j}\right)+\alpha_{j}\right] \\
\dot{x}_{j}(t)= & \alpha_{j}-\frac{\beta_{i}(t) \beta_{j}(t) \gamma_{j}}{4 \beta_{i}(t) \beta_{j}(t)-\gamma_{i} \gamma_{j}} s(t)-\frac{2 \beta_{i}(t) \beta_{j}(t)-\gamma_{i} \gamma_{j}}{4 \beta_{i}(t) \beta_{j}(t)-\gamma_{i} \gamma_{j}}\left[\beta_{j}(t)\left(c_{j}^{0}-d_{j}\right)+\alpha_{j}\right]+ \\
& \frac{\beta_{j}(t) \gamma_{j}}{4 \beta_{i}(t) \beta_{j}(t)-\gamma_{i} \gamma_{j}}\left[\beta_{i}(t)\left(c_{i}^{0}-d_{i}\right)+\alpha_{i}\right]
\end{aligned}
$$

Differentiate with respect to subsidy in Equations (19) and (20), we can obtain $\frac{\partial \dot{x}_{i}(t)}{\partial s}=\frac{2 \beta_{i}(t) \beta_{j}(t)-\gamma_{i} \gamma_{j}}{4 \beta_{i}(t) \beta_{j}(t)-\gamma_{i} \gamma_{j}} \beta_{i}(t)>0, \frac{\partial \dot{x}_{j}(t)}{\partial s}=-\frac{\beta_{i}(t) \beta_{j}(t) \gamma_{j}}{4 \beta_{i}(t) \beta_{j}(t)-\gamma_{i} \gamma_{j}}<0$. The results show that the demand rate of green products increases with the increasing subsidy level, and conversely the demand rate of conventional products shrinks with the increasing subsidy level.

\subsection{The optimal subsidy strategy}

The problem the government faces is how to determine the optimal subsidy in order to accomplish his objective, namely min $J_{g}$. The government's Hamiltonian function can be written as: 


$$
\begin{aligned}
H_{g}= & \lambda_{g}^{i} \dot{x}_{i}(t)+\lambda_{g}^{j} \dot{x}_{j}(t)+\lambda_{g}^{g} \dot{S}(t)+\phi_{g}^{i} \dot{\lambda}_{i}^{i}+\phi_{g}^{j} \dot{\lambda}_{j}^{j} \\
= & \left(\lambda_{g}^{i}+\lambda_{g}^{g} s(t)-c_{i} \phi_{g}^{i}\right)\left[\alpha_{i}-\beta_{i}(t)\left(p_{i}^{*}(t)-s(t)\right)+\gamma_{i} p_{j}^{*}(t)\right]+ \\
& \left(\lambda_{g}^{j}-c_{j} \phi_{g}^{j}\right)\left[\alpha_{j}-\beta_{j}(t) p_{j}^{*}(t)+\gamma_{j}\left(p_{i}^{*}(t)-s(t)\right)\right]
\end{aligned}
$$

The costate equations are:

$$
\begin{aligned}
& \ddot{\lambda_{g}^{g}}=-\frac{\partial H_{g}}{\partial S(t)}=0 \\
& \dot{\lambda_{g}^{i}}=-\frac{\partial H_{g}}{\partial x_{i}(t)}=-\left(\lambda_{g}^{i}+\lambda_{g}^{g} s(t)-c_{i} \phi_{g}^{i}\right) c_{i} \beta_{i} \frac{2 \beta_{i}(t) \beta_{j}(t)-\gamma_{i} \gamma_{j}}{4 \beta_{i}(t) \beta_{j}(t)-\gamma_{i} \gamma_{j}}+ \\
& \left(\lambda_{g}^{j}-c_{j} \phi_{g}^{j}\right) \frac{c_{i} \beta_{i}(t) \beta_{j}(t) \gamma_{j}}{4 \beta_{i}(t) \beta_{j}(t)-\gamma_{i} \gamma_{j}} \\
& \dot{\lambda_{g}^{j}}=-\frac{\partial H_{g}}{\partial x_{j}(t)}=\left(\lambda_{g}^{i}+\lambda_{g}^{g} s(t)-c_{i} \phi_{g}^{i}\right) \frac{c_{j} \beta_{i}(t) \beta_{j}(t) \gamma_{i}}{4 \beta_{i}(t) \beta_{j}(t)-\gamma_{i} \gamma_{j}}- \\
& \left(\lambda_{g}^{j}-c_{j} \phi_{g}^{j}\right) c_{j} \beta_{j}(t) \frac{2 \beta_{i}(t) \beta_{j}(t)-\gamma_{i} \gamma_{j}}{4 \beta_{i}(t) \beta_{j}(t)-\gamma_{i} \gamma_{j}} \\
& \dot{\phi_{g}^{i}}=-\frac{\partial H_{g}}{\partial \lambda_{i}^{i}}=-\left(\lambda_{g}^{i}+\lambda_{g}^{g} s(t)-c_{i} \phi_{g}^{i}\right) \beta_{i} \frac{2 \beta_{i}(t) \beta_{j}(t)-\gamma_{i} \gamma_{j}}{4 \beta_{i}(t) \beta_{j}(t)-\gamma_{i} \gamma_{j}}+ \\
& \left(\lambda_{g}^{j}-c_{j} \phi_{g}^{j}\right) \frac{\beta_{i}(t) \beta_{j}(t) \gamma_{j}}{4 \beta_{i}(t) \beta_{j}(t)-\gamma_{i} \gamma_{j}} \\
& \dot{\phi_{g}^{j}}=-\frac{\partial H_{g}}{\partial \lambda_{j}^{j}}=\left(\lambda_{g}^{i}+\lambda_{g}^{g} s(t)-c_{i} \phi_{g}^{i}\right) \frac{\beta_{i} s(t) \beta_{j} s(t) \gamma_{i}}{4 \beta_{i} s(t) \beta_{j} s(t)-\gamma_{i} \gamma_{j}}- \\
& \left(\lambda_{g}^{j}-c_{j} \phi_{g}^{j}\right) \beta_{j} \frac{2 \beta_{i} s(t) \beta_{j} s(t)-\gamma_{i} \gamma_{j}}{4 \beta_{i} s(t) \beta_{j} s(t)-\gamma_{i} \gamma_{j}}
\end{aligned}
$$

Equation (22) shows that $\lambda_{g}{ }^{g}$ is a constant. From transversality conditions $\lambda_{g}{ }^{g}(T)=1$, we can obtain $\lambda_{g}{ }^{g}=1$.

Using Equations (23) to (26) yields $\dot{\lambda_{g}^{i}}=c_{i} \dot{\phi}_{g}^{i}, \dot{\lambda_{g}^{j}}=c_{j} \dot{\phi}_{g}^{j}$. From transversality conditions $\lambda_{g}^{i}(T)=q_{i}, \lambda_{g}^{j}(T)=q_{j}, \varphi_{g}^{i}(T)=0, \varphi_{g}^{j}(T)=0$, we can get $\lambda_{g}^{i}-c_{i} \varphi_{g}^{i}=q_{i}, \lambda_{g}^{j}-c_{j} \varphi_{g}^{j}=q_{j}$. 
Necessary optimality conditions for the government's problem yields

$$
\begin{aligned}
\frac{\partial H_{g}}{\partial s} & =\lambda_{g}^{g}\left[\alpha_{i}-\beta_{i}\left(p_{i}^{*}(t)-s(t)\right)+\gamma_{i} p_{j}^{*}(t)\right]+ \\
& \left(\lambda_{g}^{i}+\lambda_{g}^{g} s-c_{i} \phi_{g}^{i}\right) \beta_{i}(t) \frac{2 \beta_{i}(t) \beta_{j}(t)-\gamma_{i} \gamma_{j}}{4 \beta_{i}(t) \beta_{j}(t)-\gamma_{i} \gamma_{j}}+\left(\lambda_{g}^{j}-c_{j} \phi_{g}^{j}\right) \frac{-\beta_{i}(t) \beta_{j}(t) \gamma_{j}}{4 \beta_{i}(t) \beta_{j}(t)-\gamma_{i} \gamma_{j}} \\
& =0
\end{aligned}
$$

Proposition 2. The optimal subsidy of the government is given by

$$
\begin{aligned}
s^{*}(t)= & -\frac{1}{2} q_{i}+\frac{\beta_{j}(t) \gamma_{j}}{2\left[2 \beta_{i}(t) \beta_{j}(t)-\gamma_{i} \gamma_{j}\right]} q_{j}+ \\
& \frac{1}{2}\left(c_{i}^{0}-d_{i}\right)-\frac{2 \beta_{j}(t) \alpha_{i}+\gamma_{i} \beta_{j}(t)\left(c_{j}^{0}-d_{j}\right)+\gamma_{i} \alpha_{j}}{2\left[2 \beta_{i}(t) \beta_{j}(t)-\gamma_{i} \gamma_{j}\right]}
\end{aligned}
$$

Where $d_{i}=c_{i} x_{i}(T), d_{j}=c_{j} x_{j}(T)$.

Proof. Substituting $\lambda_{g}{ }^{g}=1, \lambda_{g}{ }^{i}-c_{i} \varphi_{g}{ }^{i}=q_{i}, \lambda_{g}{ }^{j}-c_{j} \varphi_{g}{ }^{j}=q_{j}$ into Equation (27), we obtain Equation (28).

In Equation (28), $d_{i}$ and $d_{j}$ are unknown so far. We can substitute Equation (28) into Equations (17) and (18) and then solve differential equations to obtain $d_{i}$ and $d_{j}$, and make it satisfy the constraints $d_{i}=c_{i} x_{i}(T), d_{j}=c_{j} x_{j}(T)$.

Equation (26) implies that $\frac{\partial s^{*}}{\partial q_{i}}=-\frac{1}{2}, \frac{\partial s^{*}}{\partial q_{j}}=\frac{\beta_{j} \gamma_{j}}{2\left(2 \beta_{i} \beta_{j}-\gamma_{i} \gamma_{j}\right)}>0, \frac{\partial s^{*}}{\partial c_{i}^{0}}=\frac{1}{2}$. Some insights can be summarized as follows:

- The better the energy or environmental performance of green products, the higher the subsidy level should be. Thus the subsidy can further reduce the actual price that the consumers afford and weaken the price advantage of conventional products. The subsidy should increase with the decreasing energy or environmental performance of conventional products.

- The higher the initial cost of green products, the more the subsidy should be. Thus the subsidy policy can rapidly incur scale effect, reduce the cost of green products and raise its market competitiveness. 


\section{Numerical analysis}

This section uses an example to illustrate the proposed model. Let the demand rate functions of green products and conventional products respectively be: $\dot{x}_{i}(t)=20-e^{-0.01 t} p_{i}(t)+0.6 p_{j}(t), \dot{x}_{j}(t)=18-e^{0.01 t} p_{j}(t)+0.5 p_{i}(t)$, and unit cost functions be $C_{i}(t)=80-0.2 x_{i}(t), C_{j}(t)=60-0.2 x_{j}(t)$. The objective of the government is to minimize $J_{g}=x_{i}(T)+1.5 x_{j}(T)+S(T)$. Using parameters above and Equation (28) we can get the expression of subsidy $s(t)$. Then substituting expression of subsidy $s(t)$ into Equations (19) and (20) yields two differential equations. Let $T=30$. Using initial conditions $x_{i}(0)=0$ and $x_{j}(0)=0$, and solving the two differential equations we can obtain $x_{i}(T)$ and $x_{j}(T)$. Substituting known $x_{i}(T)$ and $x_{j}(T)$ into Equations (17), (18) and (28), we can get $s^{*}(t)=18.457-9.361 e^{0.01 t}, \quad p_{i}^{*}(t)=39.813-8.478 e^{0.01 t}, \quad p_{j}^{*}(t)=10.689+9.845 e^{-0.01 t}$. The optimal price and subsidy trajectories are shown in Figure 1. From the figure we can see that the optimal subsidy as well as optimal prices of the two kinds of products decreases as time goes on. The results stem from that on one side the unit cost decreases and on the other the consumers' environmental awareness increase gradually.

Substituting $s^{*}(t), \quad p_{i}^{*}(t)$ and $p_{j}^{*}(t) \quad$ into $\quad \dot{x}_{i}(t)=20-e^{-0.01 t}\left(p_{i}(t)-s(t)\right)+0.6 p_{j}(t)$, $\dot{x}_{j}(t)=18-e^{0.01 t} p_{j}(t)+0.5\left(p_{i}(t)-s(t)\right)$ yields specific expressions of the two types of product's demand rates $\dot{x}_{i}(t)$ and $\dot{x}_{j}(t)$. Figure 2 shows how the demand rates of green products and conventional products change over time. We can find that on one side the demand rate of green products increases as time goes on, and on the other side the demand rate of conventional products decreases dramatically. The underlying reason has much more to do with the combined action of the consumers' increasing environmental awareness and governmental subsidy policy. 


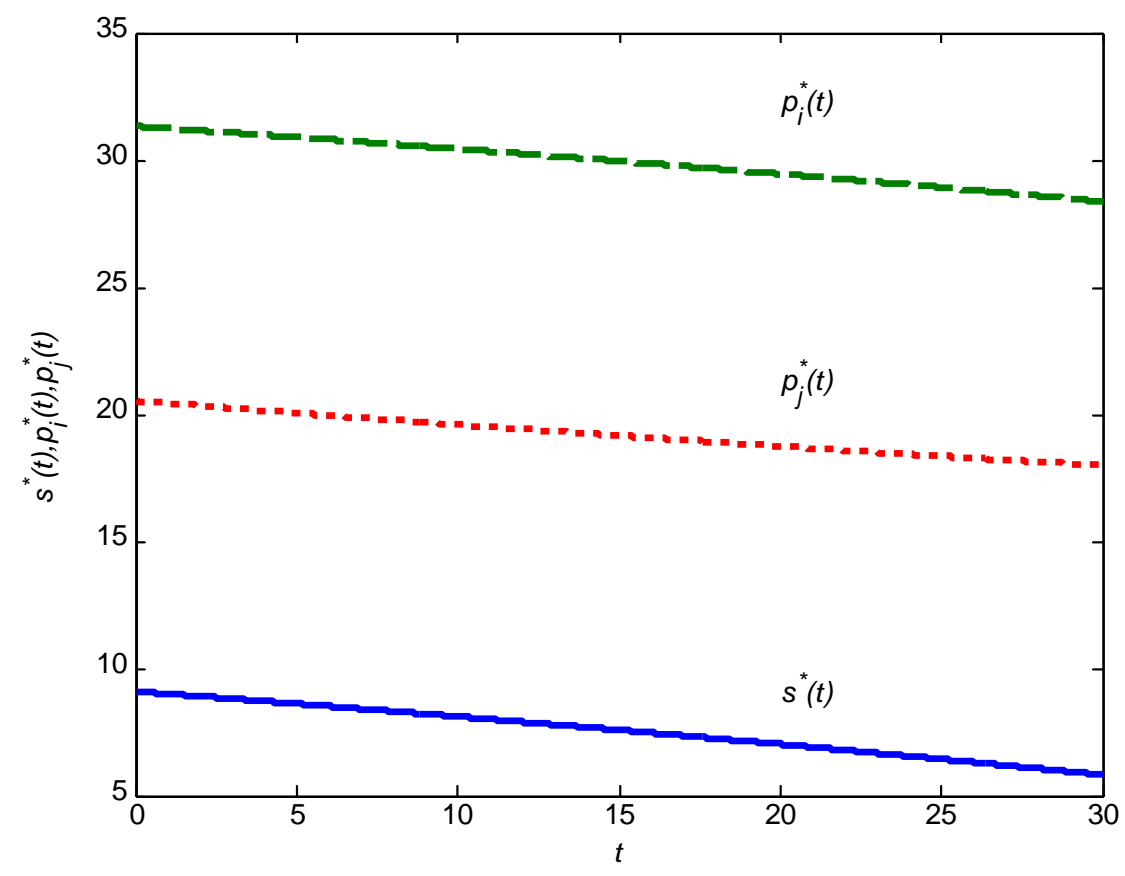

Figure 1. Optimal price and subsidy trajectories over time

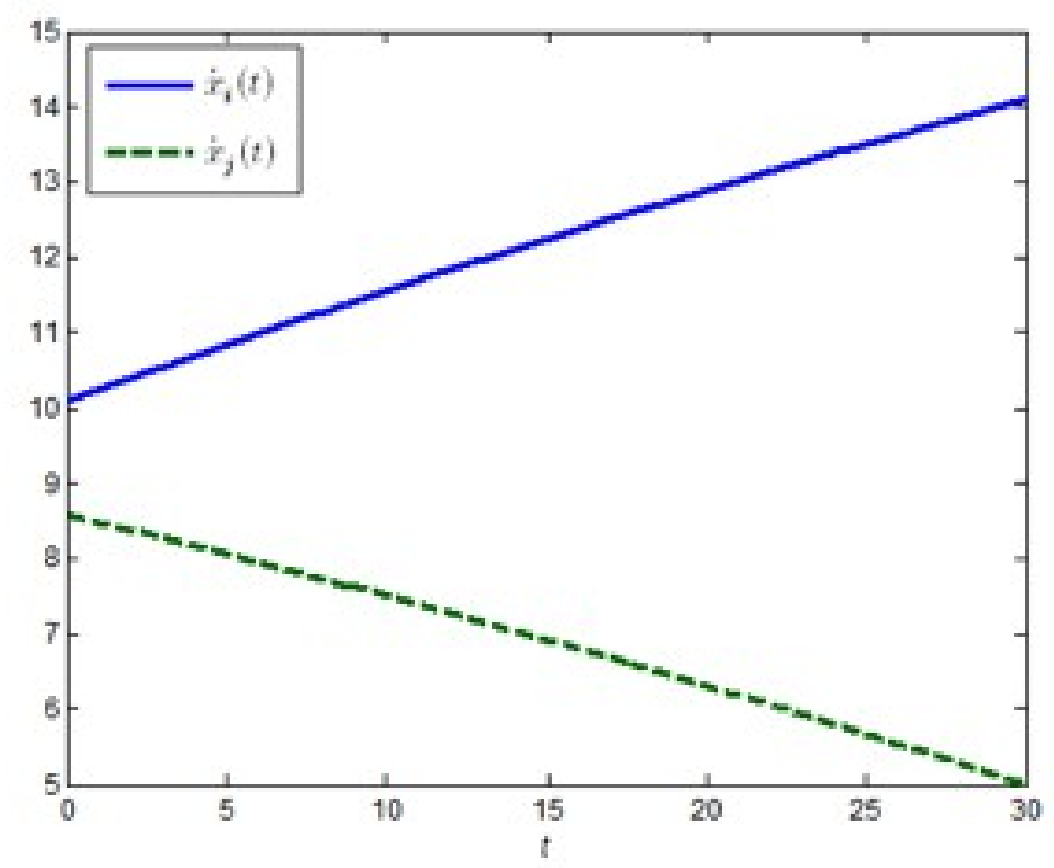

Figure 2. Demand rates over time of two types of product

\section{Conclusions}

We consider a dynamic duopoly market in which two types of product, green products and conventional products, compete over price. The government subsidizes the consumers that purchase the green product in order to trigger its adoption. We have taken a differential game approach to analyze the firms' pricing response on government's subsidy and focus upon an open-loop Stackelberg equilibrium to find the optimal subsidy policy. The results show that the more remarkable the energy saving effect, or the bigger the initial cost of green products, the 
higher the subsidy level should be. Due to the increasing environmental awareness and the learning curve, the optimal subsidy level decreases with the time. The conclusions have an important implication to policy maker.

In our model several simplifying assumptions are made to keep the analysis more tractable. In particular, we have assumed only one type of green product, so we examine a uniform policy. In reality several types of product with different energy and environmental performances exist. It must be left to further research to take into account product differentiation on energy and environmental performance and devise a discriminatory subsidy policy accordingly.

\section{Acknowledgement}

This research was supported by the Humanities \& Social Science Foundation of Ministry of Education of P.R.C. (No.09YJC630208) and the Zhejiang Philosophy and Social Sciences Foundation (No.08ZXSJ039YB).

\section{Reference}

Baines, T., Brown, S., Benedettini, O., \& Ball P. (2012). Examining Green Production and Its Role within the Competitive Strategy of Manufacturers. Journal of Industrial Engineering and Management, 5(1), 53-87. http://dx.doi.org/10.3926/jiem.405

Bass, F.M. (1969). A New Product Growth Model for Consumer Durables. Management Science, 15(1), 215-227. http://dx.doi.org/10.1287/mnsc.15.5.215

Cantono, S., \& Silverberg, G. (2009). A Percolation Model of Eco-Innovation Diffusion: The Relationship Between Diffusion, Learning Economies and Subsidies. Technological Forecasting \& Social Change, 76(4), 487-496. http://dx.doi.org/10.1016/j.techfore.2008.04.010

Cellini, R., \& Lambertini, L. (2002). A Differential Game Approach to Investment in Product Differentiation. Journal of Economic Dynamics \& Control, 27(1), 51-62. http://dx.doi.org/10.1016/S0165-1889(01)00026-4

Cesare, L.D., Liddo, A.D. (2001). A Stackelberg Game of Innovation Diffusion: Pricing, Advertising and Subsidy Strategies. International Game Theory Review, 3(4), 325-339. http://dx.doi.org/10.1142/S0219198901000476

Chang, K., Lin, W., Lee, T., \& Chung, K. (2011). Subsidy Programs on Diffusion of Solar Water Heaters: Taiwan's Experience. Energy Policy, 39(2), 563-567. http://dx.doi.org/10.1016/j.enpol.2010.10.021

Conrad, K. (2005). Price Competition and Product Differentiation When Consumers Care for the Environment. Environmental and Resource Economics, 31(1), 1-19. 
Dockner, E., \& Jørgensen, S. (1988). Optimal Pricing Strategies for New Products in Dynamic Oligopolies. Marketing Science, 7(4), 315-334. http://dx.doi.org/10.1287/mksc.7.4.315

Jørgensen, S., \& Zaccour, G. (1999). Price Subsidies and Guaranteed Buys of a New Technology. European Journal of Operational Research, 114(2), 338-345. http://dx.doi.org/10.1016/S0377-2217(98)00188-X

Kalish, S., \& Lilien, G. (1983). Optimal Price Subsidy Policy for Accelerating the Diffusion of Innovation. Marketing Science, 2(4), 407-420. http://dx.doi.org/10.1287/mksc.2.4.407

Karplus, V.J., Paltsev, S., \& Reilly, J.M. (2010). Prospects for Plug-in Hybrid Electric Vehicles in the United States and Japan: A General Equilibrium Analysis. Transportation Research Part A, 44(8), 620-641. http://dx.doi.org/10.1016/j.tra.2010.04.004

Kim, N., Bridges, E., \& Srivastava, R.K. (1999). A Simultaneous Model for Innovative Product Category Sales Diffusion and Competitive Dynamics. International Journal of Research in Marketing, 16(2), 95-111. http://dx.doi.org/10.1016/S0167-8116(98)00026-3

Lorentziadis, P.L., \& Vournas S.G. (2011). A Quantitative Model of Accelerated VehicleRetirement Induced by Subsidy. European Journal of Operational Research, 211(3), 623-629. http://dx.doi.org/10.1016/j.ejor.2011.01.029

Luthra, S., Kumar, V., Kumar, S., \& Haleem, A. (2011). Barriers to Implement Green Supply Chain Management in Automobile Industry Using Interpretive Structural Modeling TechniqueAn Indian Perspective. Journal of Industrial Engineering and Management, 4(2), 231-257. http://dx.doi.org/10.3926/jiem.2011.v4n2.p231-257

Ministry of Finance of the People's Republic of China, National Development and Reform Commission of the People's Republic of China, Ministry of Industry and Information Technology of the People's Republic of China. (2012). The Notice on the Rules On Air Conditioner Promotion of High Efficiency and Energy Saving in Energy Conservation and Benefaction to People Project. Available at: http://jjs.mof.gov.cn/zhengwuxinxi/zhengcefagui/201205/t20120528 654831.html

Orzen, H., \& Sefton, M. (2003). Buyer Subsidies in an Equilibrium Model of Price Dispersion. German Economic Review, 4(4), 497-501. http://dx.doi.org/10.1111/j.1465-6485.2003.00091.x

Peres, R., Muller, E., \& Mahajan, V. (2010). Innovation Diffusion and New Product Growth Models: A Critical Review and Research Directions. International Journal of Research in Marketing, 27(2), 91-106. http://dx.doi.org/10.1016/j.ijresmar.2009.12.012

Peterson, S.B., \& Michalek, J.J. (2013). Cost-Effectiveness of Plug-In Hybrid Electric Vehicle Battery Capacity and Charging Infrastructure Investment for Reducing US Gasoline Consumption. Energy Policy, 52, 429-438. http://dx.doi.org/10.1016/j.enpol.2012.09.059 
Sadeghi, M., \& Ameli. A. (2012). An AHP Decision Making Model for Optimal Allocation of Energy Subsidy among Socio-Economic Subsectors in Iran. Energy Policy, 45, 24-32. http://dx.doi.org/10.1016/j.enpol.2011.12.045

Toshimitsu, T. (2010). On the Paradoxical Case of a Consumer-Based Environmental Subsidy Policy. Economic Modelling, 27(1), 159-164. http://dx.doi.org/10.1016/j.econmod.2009.08.002

Zhang, Y., Song, J., \& Hamori, S. (2011). Impact of Subsidy Policies on Diffusion of Photovoltaic Power Generation. Energy Policy, 39, 1958-1964.

http://dx.doi.org/10.1016/j.enpol.2011.01.021

Journal of Industrial Engineering and Management, 2013 (www.jiem.org)

Article's contents are provided on a Attribution-Non Commercial 3.0 Creative commons license. Readers are allowed to copy, distribute and communicate article's contents, provided the author's and Journal of Industrial Engineering and Management's names are included. It must not be used for commercial purposes. To see the complete license contents, please visit http://creativecommons.org/licenses/by-nc/3.0/. 